\title{
Effectiveness of an additional individualized multi-component complementary medicine treatment on health-related quality of life in breast cancer patients: a pragmatic randomized trial
}

\author{
Witt, Claudia M ; Außerer, Oskar ; Baier, Susanne ; Heidegger, Herbert ; Icke, Katja ; Mayr, Oswald ; \\ Mitterer, Manfred ; Roll, Stephanie ; Spizzo, Gilbert ; Scherer, Arthur ; Thuile, Christian ; Wieser, \\ Anton ; Schützler, Lena
}

\begin{abstract}
The aim of this study was to evaluate the effectiveness of an additional, individualized, multicomponent complementary medicine treatment offered to breast cancer patients at the Merano Hospital (South Tyrol) on health-related quality of life compared to patients receiving usual care only. A randomized pragmatic trial with two parallel arms was performed. Women with confirmed diagnoses of breast cancer were randomized (stratified by usual care treatment) to receive individualized complementary medicine (CM group) or usual care alone (usual care group). Both groups were allowed to use conventional treatment for breast cancer. Primary endpoint was the breast cancer-related quality of life FACT-B score at 6 months. For statistical analysis, we used analysis of covariance (with factors treatment, stratum, and baseline FACT-B score) and imputed missing FACT-B scores at 6 months with regression-based multiple imputation. A total of 275 patients were randomized between April 2011 and March 2012 to the CM group $(\mathrm{n}=136,56.3 \pm 10.9$ years of age) or the usual care group $(\mathrm{n}=139$, $56.0 \pm 11.0)$. After 6 months from randomization, adjusted means for health-related quality of life were higher in the CM group (FACT-B score 107.9; $95 \%$ CI 104.1-111.7) compared to the usual care group $(102.2 ; 98.5-105.9)$ with an adjusted FACT-B score difference between groups of $5.7(2.6-8.7, \mathrm{p}<0.001)$. Thus, an additional individualized and complex complementary medicine intervention improved quality of life of breast cancer patients compared to usual care alone. Further studies evaluating specific effects of treatment components should follow to optimize the treatment of breast cancer patients.
\end{abstract}

DOI: https://doi.org/10.1007/s10549-014-3249-3

Posted at the Zurich Open Repository and Archive, University of Zurich ZORA URL: https://doi.org/10.5167/uzh-116789

Journal Article

Published Version

Originally published at:

Witt, Claudia M; Außerer, Oskar; Baier, Susanne; Heidegger, Herbert; Icke, Katja; Mayr, Oswald; Mitterer, Manfred; Roll, Stephanie; Spizzo, Gilbert; Scherer, Arthur; Thuile, Christian; Wieser, Anton; Schützler, Lena (2015). Effectiveness of an additional individualized multi-component complementary medicine treatment on health-related quality of life in breast cancer patients: a pragmatic randomized trial. Breast Cancer Research and Treatment, 149(2):449-460.

DOI: https://doi.org/10.1007/s10549-014-3249-3 


\title{
Effectiveness of an additional individualized multi-component complementary medicine treatment on health-related quality of life in breast cancer patients: a pragmatic randomized trial
}

\author{
Claudia M. Witt - Oskar Außerer - Susanne Baier - Herbert Heidegger • \\ Katja Icke • Oswald Mayr • Manfred Mitterer • Stephanie Roll • Gilbert Spizzo • \\ Arthur Scherer $\cdot$ Christian Thuile $\cdot$ Anton Wieser $\cdot$ Lena Schützler
}

Received: 10 December 2014/ Accepted: 16 December 2014/Published online: 3 January 2015

(C) Springer Science+Business Media New York 2015

\begin{abstract}
The aim of this study was to evaluate the effectiveness of an additional, individualized, multi-component complementary medicine treatment offered to breast cancer patients at the Merano Hospital (South Tyrol) on health-related quality of life compared to patients receiving usual care only. A randomized pragmatic trial with two parallel arms was performed. Women with confirmed diagnoses of breast cancer were randomized (stratified by usual care treatment) to receive individualized complementary medicine (CM group) or usual care alone (usual care group). Both groups were allowed to use conventional treatment for breast cancer. Primary endpoint was the breast cancer-related quality of life FACT-B score at 6 months. For statistical analysis, we used analysis of covariance (with factors treatment, stratum, and baseline FACT-B score) and imputed
\end{abstract}

C. M. Witt $(\bowtie)$

Institute for Complementary and Integrative Medicine,

University Hospital Zurich and University Zurich, Sonneggstr. 6, 8091 Zurich, Switzerland

e-mail: claudia.witt@uzh.ch; claudia.witt@usz.ch

C. M. Witt · K. Icke $\cdot$ S. Roll $\cdot$ L. Schützler

Institute for Social Medicine, Epidemiology and Health

Economics, Charité - Universitätsmedizin Berlin, 10098 Berlin, Germany

O. Außerer · C. Thuile

Department of Complementary Medicine, Franz Tappeiner

Hospital Merano, Rossini-Str. 5, 39012 Merano, Italy

S. Baier

Department of Medical Oncology, Hospital Bolzano , Lorenz

Böhler Str. 5, 39199 Bolzano, Italy

H. Heidegger

Department of Gynaecology and Obstetrics, Franz Tappeiner

Hospital Merano, Rossini-Str. 5, 39012 Merano, Italy missing FACT-B scores at 6 months with regression-based multiple imputation. A total of 275 patients were randomized between April 2011 and March 2012 to the CM group ( $n=136,56.3 \pm 10.9$ years of age) or the usual care group $(n=139,56.0 \pm 11.0)$. After 6 months from randomization, adjusted means for health-related quality of life were higher in the CM group (FACT-B score 107.9; $95 \%$ CI 104.1-111.7) compared to the usual care group (102.2; 98.5-105.9) with an adjusted FACT-B score difference between groups of $5.7(2.6-8.7, p<0.001)$. Thus, an additional individualized and complex complementary medicine intervention improved quality of life of breast cancer patients compared to usual care alone. Further studies evaluating specific effects of treatment components should follow to optimize the treatment of breast cancer patients.

O. Mayr

Südtiroler Sanitätsbetrieb, Bolzano, Italy

M. Mitterer · G. Spizzo

Haemato-Oncological Day Hospital, Franz Tappeiner Hospital

Merano, Rossini-Str. 5, 39012 Merano, Italy

A. Scherer

Department of Gynaecology and Obstetrics, Bressanone

Hospital, Dantestr. 51, 39042 Bressanone, Italy

A. Wieser

Department of Radiology, Franz Tappeiner Hospital Merano,

Rossini-Str. 5, 39012 Merano, Italy 
Keywords Comparative effectiveness research . Complementary medicine - Pragmatic randomized controlled trial $\cdot$ Breast cancer

\section{Introduction}

The demand for complementary medicine (CM) in cancer patients is growing [1]. In Europe, 30-40\% of cancer patients use some form of CM $[1,2]$. Women with breast cancer are the largest group [2-4] with an increasing demand [5]. The main reasons for usage are improvement of quality of life, physical and mental well-being, boosting the immune system, and alleviating side effects of the conventional treatments [2, 4, 6-8]. Dietary supplements, herbal medicines, and mind-body techniques are the most frequently used modalities [2-4, 7, 9]. There is a need to evaluate CM especially in breast cancer patients, preferably within randomized trials [10]. However, previous studies have mainly focused on single interventions, although most patients use more than one CM modality [11, 12].

In most medical fields, evidence that directly informs clinical and health policy decision making is needed [13]. Published evidence from clinical trials in oncology often differs from observations made in a usual care patient population [14]. Comparative Effectiveness Research (CER) emphasizes the comparison of different treatment options in usual care settings by including more heterogeneous patients, using less standardized treatment protocols and measuring patient-centered outcomes [15]. The Institute of Medicine in the US mentioned cancer as one priority for CER [16]. A broad spectrum of methods can be applied to CER including randomized trials [17-19]. These so-called "pragmatic trials" play an important role in CER [20] with the advantage that they maintain internal validity deriving from randomization while being designed and implemented to increase external validity. This enables a better assessment of real-world benefits and risks, and the results can guide clinical and health policy decisions [20]. Pragmatic trials do not necessarily have to be blinded or double blinded [10].

In January 2010, the regional public health system in South Tyrol (Italy) established a service for CM at the Merano Hospital planned to run for 2 years, and aiming to improve quality of life in cancer patients and patients with chronic conditions. The present study was initiated by the regional public health system to inform the decision whether or not the service should be maintained after December 2012. Therefore, the primary aim of this study was to evaluate the effectiveness of an additional, individualized, multi-component $\mathrm{CM}$ treatment offered at the Merano Hospital compared to usual care only on health-related quality of life in patients with breast cancer.

\section{Materials and methods}

Design

Following the recommendations for CER, we conducted a pragmatic randomized trial $[19,20]$. Patients were allocated to a group that received a complex individualized $\mathrm{CM}$ treatment from the service for $\mathrm{CM}$ at the Merano Hospital, Italy, in addition to usual care (CM group) or to a group that received no additional CM treatment (usual care group). The study period per patient was 6 months. The duration of the treatment varied between patients due to the highly individualized treatment, but was terminated after a maximum of 6 months. The patients of the usual care group received no $\mathrm{CM}$ treatment at the Merano Hospital during the first 6 months, but to reduce patient selection bias they were offered the respective treatment after the end of the study. The CM therapy within the study was free of charge. Usual care was conducted following oncologic guidelines and after interdisciplinary tumor boards and was covered by the patients' health insurance. The study protocol was approved by the local ethics committee of South Tyrol (statement 10/2011).

\section{Patients}

Patients with a diagnosis of breast cancer were recruited between April 2011 and March 2012 in breast cancer centers of Merano, Bressanone, and Bolzano, Italy. After meeting the inclusion criteria and providing written informed consent, they were randomized in a 1:1 ratio and stratified according to the planned usual care treatment during the study period (four strata: chemotherapy, endocrine therapy, chemotherapy and endocrine therapy, neither chemotherapy nor endocrine therapy). The randomization list was generated using the software SAS (SAS Inc., Cary NC, USA) by a statistician not further involved in the study and was embedded in a secure database. None of the study personnel had access to the randomization list before the actual allocation. Screening, randomization, and enrolling of the study participants was done at the onsite study office by a psychologist not involved in the intervention. After registration of the patient details in the database, randomization was performed using a randomization control.

Patients were included if they had a verified diagnosis of breast cancer, were receiving usual care for cancer or related symptoms at the time of the study, and were willing to refrain from CM treatment for 6 months if they were randomized to the usual care group. Exclusion criteria were a CM treatment at the Merano Hospital during the period of 6 months prior to the study, insufficient language ability, and participation in another study. 


\section{Interventions}

All patients received their usual oncological care from those breast cancer centers they were routinely seeing as part of their cancer treatment. The treatment components, the frequency, and the overall duration of the additional complex and individualized CM treatment of the CM group were highly individualized according to the patient's clinical presentation and her needs and taking into account possible interaction with conventional treatment. Components of the treatments included infusions according to the patient's hemogram and conventional treatment (with ingredients such as alpha factor, high-dosage vitamin $\mathrm{C}$, selenium, carnitine, vitamins), acupuncture (e.g., for treating pain and nausea), hyperthermia, movement therapy (e.g., qigong), enzyme therapy, laser therapy (especially for patients with oral mucositis), mistletoe therapy, orthomolecular therapy, osteopathy, phytotherapy incl. Chinese herbal medicine. Physicians, nurses, and physiotherapists of the CM service conducted the treatments.

\section{Outcome measures}

At baseline, patients' socio-demographic as well as cancerrelated data were documented. Where available, data were obtained from the hospitals' clinical health records.

The primary outcome parameter was disease-related quality of life assessed with the Functional Assessment of Cancer Therapy-Breast (FACT-B) [21] after 6 months. Secondary outcome parameters were the FACT-B after 3 months, after 3 and 6 months the FACT-General (G) [22] subscales (physical, functional, social, and emotional wellbeing), the FACT-B subscale Breast, three single items of the FACT-G (pain, sleep, and nausea), fatigue assessed with the FACIT-fatigue scale [23], health-related quality of life assessed with the SF-12 [24], and after 6 months the proportion of responders, relapse-free survival, overall survival, adverse events (AEs), and treatment interactions. AEs were extracted from clinical health records. In the CM group, AEs and possible interactions between therapies were also documented by the CM doctor as well as changes of the CM or conventional treatment due to adverse events.

Patients in the CM group were asked to rate the overall effectiveness and their satisfaction with the CM intervention after 3 and 6 months. Furthermore, at baseline, patients in the $\mathrm{CM}$ group decided together with their physicians on up to three treatment goals that were evaluated after 3 months independently by patient and physician and after 6 months by the patient only (goal attainment scaling).

Patients completed paper-pencil questionnaires at baseline, after 3 and after 6 months. The questionnaires were available in German and Italian, the official languages in South Tyrol. The patients completed the questionnaires at home and mailed them back to the study office that was responsible for all data collection. They were reminded by telephone if they failed to send back a questionnaire.

\section{Statistics}

\section{Sample size calculation}

Assuming an effect size of 0.35 (small to moderate effect) regarding the FACT-B at 6 months, a power of $80 \%$, and a two-sided $t$ test with an alpha of $0.05,130$ patients have to be included in each group. Allowing for dropouts, 280 patients were to be included in the study.

\section{Analyses}

Data analyses followed a predefined and signed statistical analysis plan (SAP) agreed upon by the Steering Committee. Socio-demographic and disease-related characteristics at baseline are presented as means with standard deviation for continuous data and frequencies with percentages for categorical data. The primary analysis of the primary endpoint (FACT-B score after 6 months) was performed by analysis of covariance (ANCOVA) including the treatment and stratum variables as fixed effects, and the baseline FACT-B score as covariate. Results for the treatment effect are presented as adjusted means for each treatment group and for the group difference, with $95 \%$ confidence intervals and the corresponding $p$ value. The $p$ value was two-sided and the type I error level was set at 0.05 . This analysis was performed on the intention-to-treat (ITT) population with multiple imputation of missing FACT-B scores after 6 months. Multiple imputation was performed using SAS PROC MI and PROC MIANALYZE (SAS for Windows Version 9.3, SAS Institute Inc., Cary, NC USA) with a Markov Chain Monte Carlo (MCMC) method stratified by treatment group. Five thousand iterations were used before the first imputation and 5,000 iterations were performed between successive imputations. The number of imputations was set to 100 . The selection of imputation variables and the primary analyses of the primary endpoint were performed blinded to treatment allocation. All further analyses (secondary outcomes, further time points, subgroups, and sensitivity analyses) were performed without missing imputations and were considered exploratory.

Sensitivity analyses for the primary endpoint included the same ANCOVA model without imputation of missing value and using the last observed FACT-B value for imputation (LOCF). In addition, the primary analysis model was extended to adjust for further characteristics at baseline (education, income, previous CM use, attitude toward CM).

Secondary endpoints were analyzed using ANCOVA by adjusting for baseline values (where available) and randomization stratum for continuous variables. For binary endpoint outcomes (e.g., proportion of responders, defined by a FACT- 
B score improved by $\geq 7$ points), logistic regression adjusted for baseline values and randomization stratum was used. Effect size for the primary endpoint (adjusted for baseline value and stratum) was calculated post hoc (not described in the SAP). Adverse events will be presented descriptively presenting number and percentage of patients with adverse events (compared between treatment groups by Chi-square test).

Predefined subgroup analyses were planned using models as described above with interaction terms between treatment group and subgroup regarding the following baseline characteristics: randomization stratum, time since first diagnosis of breast cancer, time since last recurrence, cancer stage, tumor grade, number of recurrences, age groups, and native language (German, Italian).

For the safety analysis, AEs were classified according to the Common Terminology Criteria for Adverse Events established by the US National Cancer Institute [25]. An independent samples $t$ test was conducted to compare the mean number of AEs documented in the patient's record between the two groups. The frequency distributions of the different $\mathrm{AE}$ categories in the two groups were compared via Chi-square test. The mean number of AEs that was only documented by the CM doctor, and the frequency of different AE categories of these AEs also was computed.

\section{Results}

Between April 2011 and March 2012, a total of 442 patients were screened for eligibility to participate in the study (Fig. 1). A total of 275 patients were randomized, 136 to the CM group, 139 to the usual care group. Data for the main effectiveness analysis were available for 234 patients (85\%, Fig. 1). Baseline characteristics and medical history were mostly comparable between both study groups (Table 1). The overall attitude toward CM was very

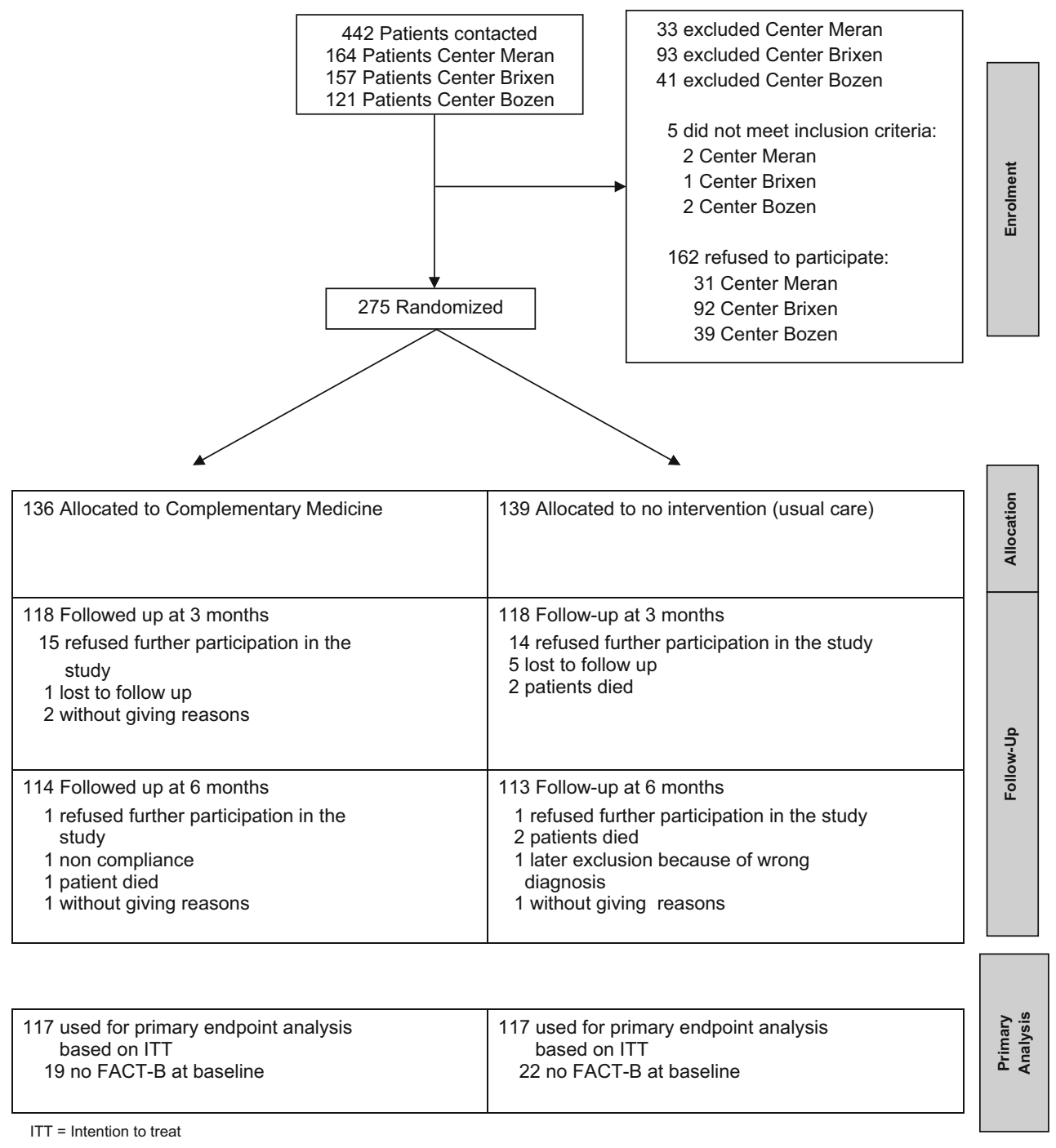

Fig. 1 CONSORT flow chart for the study 
Table 1 Baseline characteristics and medical history

\begin{tabular}{|c|c|c|}
\hline & $\begin{array}{l}\text { Complementary medicine } \\
\text { group }(n=136) \\
\text { Mean } \pm \mathrm{SD} / n(\%)\end{array}$ & $\begin{array}{l}\text { Usual care } \\
\text { group }(n=139) \\
\text { Mean } \pm \mathrm{SD} / n(\%)\end{array}$ \\
\hline Age (years) & $56.3 \pm 10.9$ & $56.0 \pm 11.0$ \\
\hline \multicolumn{3}{|l|}{ School education } \\
\hline$>10$ years of schooling & $78(60.5 \%)$ & $76(58.5 \%)$ \\
\hline \multicolumn{3}{|l|}{ Primary language } \\
\hline German & $96(70.6 \%)$ & $97(69.8 \%)$ \\
\hline Italian & $40(29.4 \%)$ & $42(30.2 \%)$ \\
\hline \multicolumn{3}{|l|}{ Family income (€/months) } \\
\hline$<2000$ Euro & $71(71.7 \%)$ & $51(55.4 \%)$ \\
\hline$\geq 2000$ Euro & $28(28.3 \%)$ & $41(44.6 \%)$ \\
\hline \multicolumn{3}{|l|}{ Breast cancer center } \\
\hline Bozen & $35(25.7 \%)$ & $46(33.1 \%)$ \\
\hline Brixen & $33(24.3 \%)$ & $32(23.0 \%)$ \\
\hline Meran & $68(50.0 \%)$ & $61(43.9 \%)$ \\
\hline Years since first diagnosis & $3.4(3.2)$ & $3.1(3.2)$ \\
\hline \multicolumn{3}{|l|}{ Tumor type } \\
\hline Carcinoma in situ & $32(23.9 \%)$ & $34(25.2 \%)$ \\
\hline Invasive ductal carcinoma & $104(77.6 \%)$ & $104(77.0 \%)$ \\
\hline Invasive lobular carcinoma & $19(14.2 \%)$ & $24(17.8 \%)$ \\
\hline Inflammatory breast cancer & $0(0 \%)$ & $0(0 \%)$ \\
\hline \multicolumn{3}{|l|}{ Tumor stage (first diagnosis or last relapse) } \\
\hline Stage 0 & $7(5.4 \%)$ & $5(3.8 \%)$ \\
\hline Stage I & $57(43.8 \%)$ & $51(38.6 \%)$ \\
\hline Stage II & $47(36.2 \%)$ & $59(44.7 \%)$ \\
\hline Stage III & $16(12.3 \%)$ & $9(6.8 \%)$ \\
\hline Stage IV & $3(2.3 \%)$ & $8(6.1 \%)$ \\
\hline \multicolumn{3}{|l|}{ Tumor grading } \\
\hline G1 & $13(10.1 \%)$ & $17(13.4 \%)$ \\
\hline $\mathrm{G} 2$ & $58(45.0 \%)$ & $56(44.1 \%)$ \\
\hline G3 & $58(45.0 \%)$ & $54(42.5 \%)$ \\
\hline \multicolumn{3}{|l|}{ Relaps } \\
\hline None & $126(92.6 \%)$ & $133(95.7 \%)$ \\
\hline 1 & $8(5.9 \%)$ & $6(4.3 \%)$ \\
\hline$\geq 2$ & $2(1.5 \%)$ & $0(0 \%)$ \\
\hline \multicolumn{3}{|l|}{ Menopause } \\
\hline Pre-/perimenopausal & $51(39.8 \%)$ & $60(46.9 \%)$ \\
\hline Postmenopausal & $77(60.2 \%)$ & $68(53.1 \%)$ \\
\hline \multicolumn{3}{|l|}{ Previous surgery } \\
\hline Breast conserving (lumpectomy or Quadrantectomy) & $112(78.0 \%)$ & $104(79.4 \%)$ \\
\hline Mastectomy & $34(25.8 \%)$ & $34(26.0 \%)$ \\
\hline Undefined surgery & $2(1.5 \%)$ & $3(2.3 \%)$ \\
\hline \multicolumn{3}{|l|}{ Previous radiation therapy } \\
\hline External radiation & $83(66.9 \%)$ & $87(73.1 \%)$ \\
\hline Brachytherapy & $1(0.8 \%)$ & $1(0.8 \%)$ \\
\hline Undefined radiation & $6(4.8 \%)$ & $4(3.4 \%)$ \\
\hline Previous chemotherapy & $62(50.8 \%)$ & $64(53.3 \%)$ \\
\hline \multicolumn{3}{|l|}{ Previous hormone therapy } \\
\hline Tamoxifen or fulvestarant & $13(11.2 \%)$ & $8(7.0 \%)$ \\
\hline
\end{tabular}


Table 1 continued

\begin{tabular}{|c|c|c|}
\hline & $\begin{array}{l}\text { Complementary medicine } \\
\text { group }(n=136) \\
\text { Mean } \pm \mathrm{SD} / n(\%)\end{array}$ & $\begin{array}{l}\text { Usual care } \\
\text { group }(n=139) \\
\text { Mean } \pm \mathrm{SD} / n(\%)\end{array}$ \\
\hline AIs & $8(6.9 \%)$ & $7(6.1 \%)$ \\
\hline LHRH analog & $7(6.0 \%)$ & $2(1.7 \%)$ \\
\hline Previous antibody therapy & $10(8.5 \%)$ & $6(5.6 \%)$ \\
\hline Previous bisphosphonate therapy & $6(5.2 \%)$ & $11(10.1 \%)$ \\
\hline \multicolumn{3}{|l|}{ Stratification group } \\
\hline Chemotherapy & $15(11.0 \%)$ & $15(10.8 \%)$ \\
\hline Hormones & $80(58.8 \%)$ & $79(56.8 \%)$ \\
\hline Chemotherapy + hormones & $1(0.7 \%)$ & $3(2.2 \%)$ \\
\hline No chemotherapy + no hormones & $40(29.4 \%)$ & $42(30.2 \%)$ \\
\hline \multicolumn{3}{|l|}{ Previous use of complementary medicine (most frequent) } \\
\hline Any & $30(22.9 \%)$ & $45(34.4 \%)$ \\
\hline Acupuncture & $11(8.4 \%)$ & $11(8.6 \%)$ \\
\hline Bach flowers & $6(4.6 \%)$ & $7(5.5 \%)$ \\
\hline Homeopathy & $12(9.2 \%)$ & $15(11.7 \%)$ \\
\hline Meditation & $2(1.5 \%)$ & $6(4.7 \%)$ \\
\hline Mistletoe & $5(3.8 \%)$ & $8(6.3 \%)$ \\
\hline Other phytomedicine & $6(4.6 \%)$ & $4(3.1 \%)$ \\
\hline Qigong/Tai Chi/Yoga & $3(2.7 \%)$ & $9(7.0 \%)$ \\
\hline Other & $17(13.0 \%)$ & $30(23.4 \%)$ \\
\hline \multicolumn{3}{|l|}{ Attitudes toward complementary medicine } \\
\hline I do not believe that it works & $3(2.3 \%)$ & $0(0 \%)$ \\
\hline Only in addition to conventional medicine & $67(52.3 \%)$ & $73(57.0 \%)$ \\
\hline Could be a good alternative to conventional medicine & $57(44.5 \%)$ & $49(38.3 \%)$ \\
\hline Overall more effective than conventional medicine & $1(0.8 \%)$ & $6(4.7 \%)$ \\
\hline FACT-B & $98.3 \pm 19.2$ & $100.7 \pm 19.5$ \\
\hline \multicolumn{3}{|l|}{ FACT-G subscales } \\
\hline Physical well-being & $20.9 \pm 5.7$ & $21.5 \pm 5.3$ \\
\hline Social and family well-being & $19.3 \pm 5.7$ & $19.5 \pm 5.8$ \\
\hline Emotional well-being & $18.1 \pm 4.0$ & $17.8 \pm 4.1$ \\
\hline Functional well-being & $17.1 \pm 5.7$ & $18.2 \pm 5.1$ \\
\hline \multicolumn{3}{|l|}{ FACT-G single items } \\
\hline Pain & $1.3 \pm 1.2$ & $1.2 \pm 1.2$ \\
\hline Sleep & $1.9 \pm 1.2$ & $2.1 \pm 1.3$ \\
\hline Nausea & $0.5 \pm 0.9$ & $0.4 \pm 0.8$ \\
\hline FACIT-fatigue scale & $36.3 \pm 11.0$ & $36.5 \pm 11.2$ \\
\hline \multicolumn{3}{|l|}{ Quality of life (SF-12) } \\
\hline Mental component scale & $44.0 \pm 10.2$ & $44.8 \pm 11.8$ \\
\hline Physical component scale & $43.9 \pm 9.7$ & $44.0 \pm 10.4$ \\
\hline
\end{tabular}

$S D$ Standard deviation, FACT-B Functional Assessment of Cancer Therapy-Breast, FACT-G Functional Assessment of Cancer Therapy General, FACIT Functional Assessment of Chronic Illness Therapy

positive, although only $23 \%$ of the patients in the CM group and $34 \%$ of patients in the usual care group had used CM before (Table 1).

During the study, patients in the CM group were individually treated (Table 2). The conventional oncological treatment was comparable in both groups and patients of both groups used CM outside the service of the Merano Hospital (Table 3).

In the primary analysis after 6 months, adjusted means for health-related quality of life were higher in the $\mathrm{CM}$ group (FACT-B score 107.9; $95 \%$ CI 104.1-111.7) compared to the usual care group $(102.2 ; 98.5-105.9)$ with an 
Table 2 Treatment in the complementary medicine group (study intervention)

Complementary medicine Mean $\pm \mathrm{SD} / n(\%)$

\begin{tabular}{ll} 
Individualized study intervention & \\
Acupuncture & $66(48.5 \%)$ \\
Number of treatments & $6.9 \pm 3.9$ \\
Dietary advice & $20(14.7 \%)$ \\
Healing touch & $1(0.7 \%)$ \\
Homeopathy & $62(45.6 \%)$ \\
Hyperthermia & $3(2.2 \%)$ \\
Infusions & $59(43.4 \%)$ \\
Number of treatments & $9.25 \pm 6.55$ \\
Laser therapy & $17(12.5 \%)$ \\
Number of treatments & $4.00 \pm 2.31$ \\
Lymphatic drainage & $4(2.9 \%)$ \\
Magnet field therapy & $19(14.0 \%)$ \\
Number of treatments & $7.6 \pm 6.1$ \\
Manual therapy & $2(1.5 \%)$ \\
Neural therapy & $8(5.9 \%)$ \\
Orthomolecular therapy & $66(48.5 \%)$ \\
Osteopathy & $26(19.1 \%)$ \\
Number of treatments & $5.7 \pm 2.7$ \\
Phytotherapy & $35(25.7 \%)$ \\
Shiatsu & $1(0.7 \%)$ \\
\hline
\end{tabular}

adjusted FACT-B score difference between groups of 5.7 (2.6-8.7, $p<0.001)$.

This improvement was robust in the sensitivity analyses for missing data and the extended model adjusting for further characteristics at baseline (data not shown). Responder rates were higher in the CM group compared to the usual care group (adjusted odds ratio 0.4, $95 \%$ CI $0.2-0.7, p=0.003$ ). The adjusted effect size for the difference between groups according to Cohen's d was 0.53. No subgroup showed a significant effect modifying influence regarding FACT-B at 6 months.

For most secondary outcomes, the results of the patients in the $\mathrm{CM}$ group were superior to those in the usual care group (Table 4). Three patients died during the study ( 1 in the $\mathrm{CM}$ group and 2 in the usual care group, Fig. 1), and one relapse occurred in the usual care group. Before the intervention, patients in the $\mathrm{CM}$ group defined with their physicians on average $2.6 \pm 0.7$ treatment goals and assessed those after 3 and 6 months. (Table 5). The patients were mostly satisfied with the $\mathrm{CM}$ treatment and found it effective (Table 5).

\section{Safety}

The mean number of AEs documented in the patient's records was $0.52(\mathrm{SD}=1.14)$ in the $\mathrm{CM}$ group and 0.64
(2.10) in the usual care group $(p=0.56)$. Most AEs belonged to the spectrum of musculoskeletal and connective tissue disorders $(22.5 \%)$, gastrointestinal disorders $(13.1 \%)$, and general disorders $(13.1 \%)$, with no significant difference between groups $(p=0.41$, Table 6). The additional documentation for the $\mathrm{CM}$ patients resulted in a mean number of $2.92(\mathrm{SD}=1.63)$ AEs per patient. Most of these AEs were musculoskeletal and connective tissue disorders $(24.4 \%)$, followed by psychiatric disorders (20.4\%), and general disorders (16.1\%) (Table 6). For two patients in the $\mathrm{CM}$ group, the $\mathrm{CM}$ treatment was changed due to AEs, and for two patients in the usual care group, the conventional treatment was changed due to AEs.

\section{Discussion}

Breast cancer patients treated with an individualized multicomponent CM treatment at the Merano Hospital showed significant improvements in disease-specific quality of life and fatigue compared with patients who received standard care alone.

To our knowledge, the present study is the first randomized trial in breast cancer patients evaluating the effectiveness of a complex and individualized CM intervention in a usual care setting. We used the framework of CER and designed a pragmatic trial [19] that allowed us to answer the question if the CM service implemented by the regional public health system had a positive effect on quality of life of cancer patients and should be maintained.

We focused on breast cancer patients because they made up the largest group using the respective service. Thus the study results cannot be transferred to other patients. Furthermore, the results relate to the specific interventions and setting of the Hospital Merano and cannot be transferred to other interventions and settings.

Advantages of our approach to provide useful information for decision making regarding continuation of the service included an outcome measure that was recommended for incorporating patient-reported outcomes into CER [26], a setting and intervention that reflected usual care, broad eligibility criteria, and the participation of all existing breast cancer centers in the region.

Clearly, this kind of approach also has methodological limitations. Neither physicians nor patients were blinded to treatment. To minimize social acceptability bias, all questionnaires were sent directly from and to the psychologist who was not further involved in the patients' treatment. However, bias regarding the patient-reported main outcome resulting from non-blinding to the intervention cannot be ruled out. Also, there might be bias attributable to participating physicians' and practitioners' positive attitudes about CM, their affiliation with the governmental 
Table 3 Concomitant treatments in both groups

\begin{tabular}{|c|c|c|c|c|}
\hline & \multicolumn{2}{|c|}{$\begin{array}{l}\text { Complementary } \\
\text { medicine } n(\%)\end{array}$} & \multicolumn{2}{|c|}{ Usual care $n(\%)$} \\
\hline & 3 months & 6 months & 3 months & 6 months \\
\hline \multicolumn{5}{|l|}{ Complementary medicine outside the study } \\
\hline Any & $11(9.6 \%)$ & $19(16.8 \%)$ & $27(23.7 \%)$ & $25(22.5 \%)$ \\
\hline Acupuncture & $4(3.5 \%)$ & $4(3.5 \%)$ & $5(4.5 \%)$ & $2(1.8 \%)$ \\
\hline Bach flowers & $1(0.9 \%)$ & $1(0.9 \%)$ & $2(1.8 \%)$ & $2(1.8 \%)$ \\
\hline Homeopathy & $8(7.0 \%)$ & $7(6.2 \%)$ & $10(8.9 \%)$ & $6(5.5 \%)$ \\
\hline Meditation & $1(0.9 \%)$ & $4(3.5 \%)$ & $4(3.6 \%)$ & $5(4.6 \%)$ \\
\hline Mistletoe & $3(2.6 \%)$ & $4(3.5 \%)$ & $3(2.7 \%)$ & $5(4.6 \%)$ \\
\hline Other phytomedicine & $1(0.9 \%)$ & $2(1.8 \%)$ & $4(3.6 \%)$ & $2(1.8 \%)$ \\
\hline Qigong/Tai Chi/Yoga & $2(1.8 \%)$ & $5(4.4 \%)$ & $5(4.5 \%)$ & $7(6.4 \%)$ \\
\hline Other & $9(7.8 \%)$ & $14(12.6 \%)$ & $19(16.9 \%)$ & $17(15.6 \%)$ \\
\hline \multicolumn{5}{|l|}{ Usual care cancer treatment } \\
\hline \multicolumn{5}{|l|}{ Surgery } \\
\hline $\begin{array}{l}\text { Breast conserving surgery } \\
\text { (Lumpectomy or Quadrantectomy) }\end{array}$ & $0(0 \%)$ & & $0(0 \%)$ & \\
\hline Mastectomy & $1(0.8 \%)$ & & $1(0.8 \%)$ & \\
\hline Undefined surgery & $1(0.8 \%)$ & & $1(0.8 \%)$ & \\
\hline \multicolumn{5}{|l|}{ Radiation therapy } \\
\hline External & $10(8.1 \%)$ & & $7(5.9 \%)$ & \\
\hline Brachytherapie & $0(0 \%)$ & & $0(0 \%)$ & \\
\hline Undefined & $1(0.8 \%)$ & & $2(1.7 \%)$ & \\
\hline Chemotherapy & $8(6.6 \%)$ & & $10(8.3 \%)$ & \\
\hline \multicolumn{5}{|l|}{ Hormone therapy } \\
\hline Tamoxifen o. fulvestarant & $27(23.5 \%)$ & & $25(21.7 \%)$ & \\
\hline AIs & $51(44.3 \%)$ & & $51(44.3 \%)$ & \\
\hline LHRH analog & $18(15.7 \%)$ & & $17(14.8 \%)$ & \\
\hline Antibody therapy & $6(5.1 \%)$ & & $7(6.5 \%)$ & \\
\hline Bisphosphonates & $3(2.6 \%)$ & & $1(0.9 \%)$ & \\
\hline Patients in hospital (patient reported) & $10(9.0 \%)$ & & $9(8.5 \%)$ & \\
\hline
\end{tabular}

project, and possible personal or financial interests in producing results in favor of CM. Our inclusion criteria were broad, which resulted in a heterogeneous patient sample and diagnostic misclassification can happen in this type of study. We had one patient claiming to have breast cancer, who was randomized to the usual care group. When comparing her interview data with the clinical health records, the diagnosis could not be confirmed. Using a more conservative approach by strictly following ITT analyses, we included her in the primary analysis, but performed an additional sensitivity analysis without this patient, which did not change the results. That not all patients received the treatment that was planned at baseline cannot be avoided in a study that reflects usual care.

Finally, our patients had a highly positive attitude toward CM treatment. However, adjusting for attitude in a sensitivity analysis did not change the main outcome. Although the issues mentioned above are considered limitations from an experimental perspective, the study design was chosen to reflect general medical practice as closely as possible. A more experimental approach would not have been suitable to answer the study question.

It is important to highlight that this study does not provide any information on the effectiveness of the single $\mathrm{CM}$ modalities used within the complex intervention. Further studies separating different modalities, perhaps multi-armed studies would be needed to generate evidence on this question. In fact, there are studies on single complementary treatment modalities for breast cancer patients, e.g., on acupuncture used for the alleviation of symptoms caused by aromatase inhibitors [27-29], or for treating cancer-related fatigue [30, 31].

Furthermore, this study cannot answer the question of how much of the observed effects can be attributed to nonspecific effects. Based on evidence that some of the interventions have relevant non-specific effects (i.e. acupuncture) [32], those also contribute to our results. The numbers of AEs were low and did not differ in both groups. 


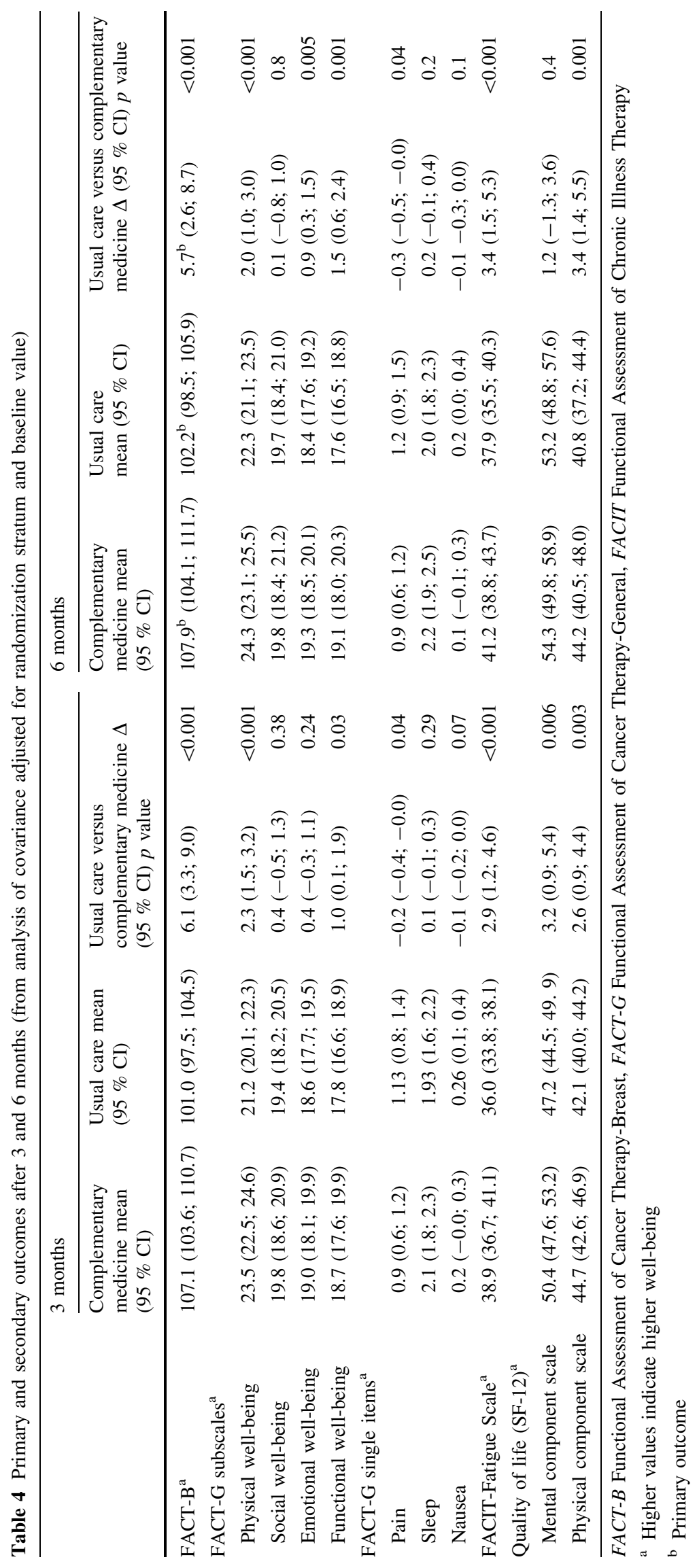


Table 5 Complementary medicine group: patients overall rating of effectiveness, satisfaction, and goal attainment scaling at 3 and 6 months

\begin{tabular}{llll}
\hline Variable & 3 months & & 6 months \\
\cline { 2 - 3 } & Patient & Physician & Patient \\
\hline Goal attainment scaling & (mean \pm SD) & & \\
Goal 1 & $0.4 \pm 1.0$ & $0.4 \pm 0.8$ & $0.3 \pm 1.0$ \\
Goal 2 & $0.3 \pm 1.0$ & $0.2 \pm 0.8$ & $0.4 \pm 1.0$ \\
Goal 3 & $0.1 \pm 1.0$ & $0.1 \pm 0.8$ & $0.2 \pm 1.0$ \\
Average of goal-1-3 & $0.3 \pm 1.0$ & $0.3 \pm 0.8$ & $0.3 \pm 1.0$ \\
Rating of effectiveness & & & \\
Very effective & $18(15.3 \%)$ & & $23(20.2 \%)$ \\
Effective & $88(74.6 \%)$ & & $83(72.8 \%)$ \\
Small effect & $12(10.2 \%)$ & & $7(6.1 \%)$ \\
No effect & $0(0 \%)$ & & $1(0.9 \%)$ \\
Satisfaction with CM treatment & & \\
Very satisfied & $50(42.7 \%)$ & & $38(33.3 \%)$ \\
Satisfied & $58(49.6 \%)$ & & $68(59.6 \%)$ \\
Not very satisfied & $9(7.7 \%)$ & & $7(6.1 \%)$ \\
Not satisfied & $0(0 \%)$ & & $1(0.9 \%)$ \\
\hline
\end{tabular}

a -2 points worse than expected, -1 no change, 0 aim reached, 1 better than expected, 2 much better than expected

Table 6 Number of adverse events in both groups

\begin{tabular}{|c|c|c|c|}
\hline & $\begin{array}{l}\text { CM group } \\
n(\%)\end{array}$ & $\begin{array}{l}\text { Usual care } \\
\text { group } \\
n(\%)\end{array}$ & $\begin{array}{l}\text { Total } \\
n(\%)\end{array}$ \\
\hline \multicolumn{4}{|c|}{ AEs documented in clinical records } \\
\hline $\begin{array}{l}\text { Blood and lymphatic } \\
\text { system disorders }\end{array}$ & $1(1.4 \%)$ & $3(3.4 \%)$ & $4(2.5 \%)$ \\
\hline $\begin{array}{l}\text { Ear and labyrinth } \\
\text { disorders }\end{array}$ & $1(1.4 \%)$ & $1(1.1 \%)$ & $2(1.2 \%)$ \\
\hline $\begin{array}{l}\text { Gastrointestinal } \\
\text { disorders }\end{array}$ & ${ }^{11}(15.5 \%)$ & $\begin{array}{l}10 \\
(11.2 \%)\end{array}$ & $\begin{array}{l}21 \\
\quad(13.1 \%)\end{array}$ \\
\hline $\begin{array}{l}\text { General disorders and } \\
\text { administration site } \\
\text { conditions }\end{array}$ & $8(11.3 \%)$ & $\begin{array}{l}13 \\
(14.6 \%)\end{array}$ & $\begin{array}{l}21 \\
(13.1 \%)\end{array}$ \\
\hline Hepatobiliary disorders & $1(1.4 \%)$ & $0(0.0 \%)$ & $1(0.6 \%)$ \\
\hline $\begin{array}{l}\text { Immune system } \\
\text { disorders }\end{array}$ & $1(1.4 \%)$ & $0(0.0 \%)$ & $1(0.6 \%)$ \\
\hline $\begin{array}{l}\text { Infections and } \\
\text { infestations }\end{array}$ & $6(8.5 \%)$ & $2(2.2 \%)$ & $8(5.0 \%)$ \\
\hline $\begin{array}{l}\text { Injury, poisoning and } \\
\text { procedural } \\
\text { complications }\end{array}$ & $2(2.8 \%)$ & $0(0.0 \%)$ & $2(1.2 \%)$ \\
\hline Investigations & $1(1.4 \%)$ & $2(2.2 \%)$ & $3(1.9 \%)$ \\
\hline $\begin{array}{l}\text { Metabolisms and } \\
\text { nutrition disorders }\end{array}$ & $0(0.0 \%)$ & $1(1.1 \%)$ & $1(0.6 \%)$ \\
\hline $\begin{array}{l}\text { Musculoskeletal and } \\
\text { connective tissue } \\
\text { disorders }\end{array}$ & $\begin{array}{l}16 \\
(22.5 \%)\end{array}$ & $\begin{array}{l}20 \\
(22.5 \%)\end{array}$ & $\begin{array}{l}36 \\
\quad(22.5 \%)\end{array}$ \\
\hline
\end{tabular}

Table 6 continued

\begin{tabular}{|c|c|c|c|}
\hline & $\begin{array}{l}\text { CM group } \\
n(\%)\end{array}$ & $\begin{array}{l}\text { Usual care } \\
\text { group } \\
n(\%)\end{array}$ & $\begin{array}{l}\text { Total } \\
n(\%)\end{array}$ \\
\hline $\begin{array}{l}\text { Nervous system } \\
\text { disorders }\end{array}$ & $8(11.3 \%)$ & $6(6.7 \%)$ & $14(8.8 \%)$ \\
\hline Psychiatric disorders & $3(4.2 \%)$ & 12 & $15(9.4 \%)$ \\
\hline $\begin{array}{l}\text { Renal and urinary } \\
\text { disorders }\end{array}$ & $0(0.0 \%)$ & $1(1.1 \%)$ & $1(0.6 \%)$ \\
\hline $\begin{array}{l}\text { Reproductive system } \\
\text { and breast disorders }\end{array}$ & $2(2.8 \%)$ & $5(5.6 \%)$ & $7(4.4 \%)$ \\
\hline $\begin{array}{l}\text { Respiratory thoracic and } \\
\text { mediastinal disorders }\end{array}$ & $1(1.4 \%)$ & $0(0.0 \%)$ & $1(0.6 \%)$ \\
\hline $\begin{array}{l}\text { Skin and subcutaneous } \\
\text { tissue disorders }\end{array}$ & $5(7.0 \%)$ & $6(6.7 \%)$ & $11(6.9 \%)$ \\
\hline Vascular disorders & $4(5.6 \%)$ & $6(6.7 \%)$ & $10(6.2 \%)$ \\
\hline No code available & $0(0.0 \%)$ & $1(1.1 \%)$ & $1(0.6 \%)$ \\
\hline Total & $\begin{array}{l}71 \\
(100.0 \%)\end{array}$ & $\begin{array}{l}89 \\
(100.0 \%)\end{array}$ & $\begin{array}{l}160 \\
(100.0 \%)\end{array}$ \\
\hline
\end{tabular}

AEs documented by $\mathrm{CM}$ doctor

$\begin{array}{ll}\text { Ear and labyrinth } & 8(2.0) \\ \text { disorders } & \\ \text { Endocrine disorders } & 1(0.3) \\ \text { Eye disorders } & 4(1.0) \\ \text { Gastrointestinal } & 31(7.8) \\ \quad \text { disorders } & \\ \text { General disorders and } & 64(16.1) \\ \text { administration site } & \\ \text { conditions } & \\ \begin{array}{l}\text { Immune system } \\ \text { disorders }\end{array} & 5(1.3) \\ \begin{array}{l}\text { Infections and } \\ \text { infestations }\end{array} & 6(1.5) \\ \begin{array}{l}\text { Investigations } \\ \text { Metabolisms and } \\ \text { nutrition disorders }\end{array} & 1(0.3) \\ \text { Musculoskeletal and } \\ \text { connective tissue } \\ \text { disorders }\end{array}$


In usual care, physicians ask their patients less detailed questions about AEs than in clinical trials and even if patients report them, they might not always be documented [33]. In the CM group, the doctors asked explicitly for AEs, resulting in additionally documented AEs, especially psychiatric disorders including anxiety, worries, sleeping problems, or restlessness. This might be explained by the holistic approach of CM doctors asking for both mind and body aspects.

It is difficult to compare our study with other studies because previous studies addressed mainly single $\mathrm{CM}$ modalities, for example, yoga [34] or specific intervention programs such as mind-body medicine $[35,36]$. There are only few studies that address the topic of complex individualized $\mathrm{CM}$ interventions in cancer patients in usual care setting, and none of them used a randomized design $[3,37,38]$.

\section{Conclusion}

The additional individualized and complex $\mathrm{CM}$ intervention offered by the Hospital Merano was more effective in improving quality of life compared to no additional CM intervention in breast cancer patients. Further studies evaluating the effectiveness, efficacy, and safety of treatment components should follow.

Acknowledgments We thank Dr. Claudio Graiff who participated in the advisory board and Dr. Angelina Bockelbrink for her work in preparing this study. Furthermore, we like to thank Dr. Markus Horneber for his helpful comments on the study protocol and Sylvia Binting for her support in categorizing the adverse event.

Funding information This study was funded by the Federal State Government Trentino-Alto Adige (decision 37/2009).

Conflict of interest Oskar Ausserer received remuneration from the Südtiroler Sanitätsbetrieb.

\section{References}

1. Horneber M, Bueschel G, Dennert G, Less D, Ritter E, Zwahlen M (2012) How many cancer patients use complementary and alternative medicine: a systematic review and metaanalysis. Integr Cancer Ther 11(3):187-203

2. Molassiotis A, Fernadez-Ortega P, Pud D, Ozden G, Scott JA, Panteli V, Margulies A, Browall M, Magri M, Selvekerova S, Madsen E, Milovics L, Bruyns I, Gudmundsdottir G, Hummerston S, Ahmad AM, Platin N, Kearney N, Patiraki E (2005) Use of complementary and alternative medicine in cancer patients: a European survey. Ann Oncol 16(4):655-663

3. Kang E, Yang EJ, Kim SM, Chung IY, Han SA, Ku DH, Nam SJ, Yang JH, Kim SW (2012) Complementary and alternative medicine use and assessment of quality of life in Korean breast cancer patients: a descriptive study. Support Care Cancer 20(3):461-473
4. Morris KT, Johnson N, Homer L, Walts D (2000) A comparison of complementary therapy use between breast cancer patients and patients with other primary tumor sites. Am J Surg 179(5):407-411

5. Boon HS, Olatunde F, Zick SM (2007) Trends in complementary/ alternative medicine use by breast cancer survivors: comparing survey data from 1998 and 2005. BMC Womens Health 7:4

6. McLay JS, Stewart D, George J, Rore C, Heys SD (2012) Complementary and alternative medicines use by Scottish women with breast cancer. What, why and the potential for drug interactions? Eur J Clin Pharmacol 68(5):811-819

7. Sewitch MJ, Yaffe M, Maisonneuve J, Prchal J, Ciampi A (2011) Use of complementary and alternative medicine by cancer patients at a Montreal hospital. Integr Cancer Ther 10(4):305-311

8. von Gruenigen VE, Frasure HE, Jenison EL, Hopkins MP, Gil KM (2006) Longitudinal assessment of quality of life and lifestyle in newly diagnosed ovarian cancer patients: the roles of surgery and chemotherapy. Gynecol Oncol 103(1):120-126

9. Navo MA, Phan J, Vaughan C, Palmer JL, Michaud L, Jones KL, Bodurka DC, Basen-Engquist K, Hortobagyi GN, Kavanagh JJ, Smith JA (2004) An assessment of the utilization of complementary and alternative medication in women with gynecologic or breast malignancies. J Clin Oncol 22(4):671-677

10. Walker LG, Anderson J (1999) Testing complementary and alternative therapies within a research protocol. Eur J Cancer 35(11):1614-1618

11. Balneaves LG, Bottorff JL, Hislop TG, Herbert C (2006) Levels of commitment: exploring complementary therapy use by women with breast cancer. J Altern Complement Med 12(5):459-466

12. Shumay DM, Maskarinec G, Gotay CC, Heiby EM, Kakai H (2002) Determinants of the degree of complementary and alternative medicine use among patients with cancer. J Altern Complement Med 8(5):661-671

13. Brouwers MC, Thabane L, Moher D, Straus SE (2012) Comparative effectiveness research paradigm: implications for systematic reviews and clinical practice guidelines. J Clin Oncol 30(34):4202-4207

14. Mullins CD, Montgomery R, Tunis S (2010) Uncertainty in assessing value of oncology treatments. Oncologist 15(Suppl 1):58-64. doi:10.1634/theoncologist.:58-64

15. Institute of Medicine (2009) Advising the nation. Improving health. The National Academies Press, Washington D.C

16. Iglehart JK (2009) Prioritizing comparative-effectiveness research-IOM recommendations. N Engl J Med 361(4):325-328

17. Tunis SR, Benner J, McClellan M (2010) Comparative effectiveness research: policy context, methods development and research infrastructure. Stat Med 29(19):1963-1976

18. Tunis SR, Stryer DB, Clancy CM (2003) Practical clinical trials: increasing the value of clinical research for decision making in clinical and health policy. JAMA 290(12):1624-1632

19. Zwarenstein M, Treweek S, Gagnier JJ, Altman DG, Tunis S, Haynes B, Oxman AD, Moher D (2008) Improving the reporting of pragmatic trials: an extension of the CONSORT statement. BMJ 337:a2390

20. Chalkidou K, Tunis S, Whicher D, Fowler R, Zwarenstein M (2012) The role for pragmatic randomized controlled trials (pRCTs) in comparative effectiveness research. Clin Trials 9(4):436-446

21. Brady MJ, Cella DF, Mo F, Bonomi AE, Tulsky DS, Lloyd SR, Deasy S, Cobleigh M, Shiomoto G (1997) Reliability and validity of the Functional Assessment of Cancer Therapy-Breast qualityof-life instrument. J Clin Oncol 15(3):974-986

22. Cella DF, Tulsky DS, Gray G, Sarafian B, Linn E, Bonomi A, Silberman M, Yellen SB, Winicour P, Brannon J (1993) The Functional Assessment of Cancer Therapy scale: development and validation of the general measure. J Clin Oncol 11(3):570-579 
23. Yellen SB, Cella DF, Webster K, Blendowski C, Kaplan E (1997) Measuring fatigue and other anemia-related symptoms with the Functional Assessment of Cancer Therapy (FACT) measurement system. J Pain Symptom Manage 13(2):63-74

24. Ware JE Jr (1976) SF-36 health survey update. Spine 25(24):3130-3139

25. National Cancer Institute (2014) NCI Term Browser. Available at: http://nciterms.nci.nih.gov/ncitbrowser/pages/vocabulary.jsf? dictionary $=$ Common $\% 20$ Terminology $\% 20$ Criteria $\% 20$ for $\% 20$ Adverse\%20Events\&version=4.03\#. Retrieved Dec 2014

26. Basch E, Abernethy AP, Mullins CD, Reeve BB, Smith ML, Coons SJ, Sloan J, Wenzel K, Chauhan C, Eppard W, Frank ES, Lipscomb J, Raymond SA, Spencer M, Tunis S (2012) Recommendations for incorporating patient-reported outcomes into clinical comparative effectiveness research in adult oncology. J Clin Oncol 30(34):4249-4255

27. Crew KD, Capodice JL, Greenlee H, Brafman L, Fuentes D, Awad D, Yann TW, Hershman DL (2010) Randomized, blinded, sham-controlled trial of acupuncture for the management of aromatase inhibitor-associated joint symptoms in women with early-stage breast cancer. J Clin Oncol 28(7):1154-1160

28. Mao JJ, Xie SX, Farrar JT, Stricker CT, Bowman MA, Bruner D, DeMichele A (2014) A randomised trial of electro-acupuncture for arthralgia related to aromatase inhibitor use. Eur J Cancer 50(2):267-276

29. Bao T, Cai L, Snyder C, Betts K, Tarpinian K, Gould J, Jeter S, Medeiros M, Chumsri S, Bardia A, Tan M, Singh H, Tkaczuk KH, Stearns V (2014) Patient-reported outcomes in women with breast cancer enrolled in a dual-center, double-blind, randomized controlled trial assessing the effect of acupuncture in reducing aromatase inhibitor-induced musculoskeletal symptoms. Cancer 120(3):381-389

30. Molassiotis A, Bardy J, Finnegan-John J, Mackereth P, Ryder DW, Filshie J, Ream E, Richardson A (2012) Acupuncture for cancer-related fatigue in patients with breast cancer: a pragmatic randomized controlled trial. J Clin Oncol 30(36):4470-4476

31. Smith C, Carmady B, Thornton C, Perz J, Ussher JM (2013) The effect of acupuncture on post-cancer fatigue and well-being for women recovering from breast cancer: a pilot randomised controlled trial. Acupunct Med 31(1):9-15

32. Linde K, Niemann K, Schneider A, Meissner K (2010) How large are the nonspecific effects of acupuncture? A meta-analysis of randomized controlled trials. BMC Med 8:75

33. Weissman JS, Schneider EC, Weingart SN, Epstein AM, DavidKasdan J, Feibelmann S, Annas CL, Ridley N, Kirle L, Gatsonis C (2008) Comparing patient-reported hospital adverse events with medical record review: do patients know something that hospitals do not? Ann Intern Med 149(2):100-108

34. Bower JE, Garet D, Sternlieb B, Ganz PA, Irwin MR, Olmstead R, Greendale G (2012) Yoga for persistent fatigue in breast cancer survivors: a randomized controlled trial. Cancer 118(15): 3766-3775

35. Levine EG, Eckhardt J, Targ E (2005) Change in post-traumatic stress symptoms following psychosocial treatment for breast cancer. Psychooncology 14(8):618-635

36. Targ EF, Levine EG (2002) The efficacy of a mind-body-spirit group for women with breast cancer: a randomized controlled trial. Gen Hosp Psychiatry 24(4):238-248

37. Saquib J, Madlensky L, Kealey S, Saquib N, Natarajan L, Newman VA, Patterson RE, Pierce JP (2011) Classification of CAM use and its correlates in patients with early-stage breast cancer. Integr. Cancer Ther 10(2):138-147

38. Beatty LJ, Adams J, Sibbritt D, Wade TD (2012) Evaluating the impact of cancer on complementary and alternative medicine use, distress and health related QoL among Australian women: a prospective longitudinal investigation. Complement Ther Med 20(1-2):61-69 